predispose to disruption of interpersonal relationships, and (2) this childhood experience may make individuals abnormally vulnerable to the loss of a loved person in later life, thus precipitating suicidal reactions.

These tentative propositions, and the findings upon which they are based, obviousiy require verification. If confirmed, they raise a number of fundamental questions concerning the psychological mechanisms whereby parental loss contributes to the disruption of interpersonal relations and sensitizes certain individuals to this situation. Clearly, further research in this area is indicated.

\section{Summary}

A consecutive series of 156 attempted suicides admitted to hospital were compared with (1) non-suicidal psychiatric patients and (2) medical, surgical, and obstetric patients without psychiatric disorder in respect of salient variables in their past and present environment. Controls were matched with attempted suicides for age, sex, social class, country of origin, and, in the case of psychiatric patients, diagnosis.

Attempted suicides differed significantly from both control groups in having a greater incidence of childhood parental loss, and such loss more commonly involved both parents, occurred at a younger age, and was more likely to be permanent (i.e., due to parental death and divorce). The sex of the absent parent and the childhood environment after parental loss were not correlated with attempted suicide.

With regard to the immediate environment, a significantly higher proportion of attempted suicides than controls had experienced recent disruption of a close relationship due to interpersonal conflict. No significant differences were observed between the suicidal and control groups in terms of $(a)$ social isolation (i.e., living alone), (b) psychological isolation (i.e., the absence of any close interpersonal relationships), (c) material circumstances, or $(d)$ physical illness.

Recent disruption of close relationships was found to be correlated with parental loss. Possible ways in which these variables may contribute to suicidal behaviour are considered. The need for verification of present findings is stressed. The same study is being conducted on an American hospita! population by other workers, and their findings are awaited with interest.

We are grateful to Professor J. Anderson, medical unit, and Dr. D. Liddell, head of the department of psychological medicine, fo: their advice and encouragement. Our thanks are also due to the consultants at King's College and Dulwich Hospitals who kindly allowed us to interview patients under their care, and to Mrs. $\mathbf{R}$ Badham for secretarial work.

\section{REFERENCES}

American Psychiatric Association (1952). Diagnostic and Statistical Manual of Mental Disorders. Washington.

Bruhn, J. G. (1962). F. ment. Sci., 108, 772 .

Carstairs, G. M. (1961). Proc. roy. Soc. Med., 54, 262.

- and Brown, G. W. (1958). Ұ. ment. Sci., 104, 72

Dahlgren, K. G. (1945). On Suicide and Attempted Suicide. Lund.

Dorpat, T. L., Jackson, J. K., and Ripley, H. S. (1965). Arch. ger. Psychiat., 12, 213.

General Register Office (1960). Classification of Occupations. H.M.S.O., London.

Greer, S. (1964). Brit. F. Psychiat., 110, 698.

Harring6). Ibid., 112, 465 .

Harrington, J. A., and Cross, K. W. (1959). Brit. med. 7., 2, 463.

Kessel, N.' (1965). Ibid., 2, 1265.

Parkin, D., and Stengel, E. (1905). Ibid., 2, 133.

Rüegsegger, P. (1963̄). Psychrat. et Neurol. (Basel), 146, 81.

Sainsbury, P. (1955). Suicide in London, Maudsley Monogr. No. I London.

Schneider, P. B. (1954). La Tentative de Suicide. Neuchatel.

Schneidman, E. S., and Farberow, N. L. (editors) (1961). In The Ory for Help, Chap. 3. New York.

Stengel, E. (1956). Canad. med. Ass. F., 74, 116.
(1964). Suicide and Attempted Suicide, p. 72. Penguin Books. - Cook, N. G., and Kreeger, I. S. (1958). Attempted Suicide Maudsley Monogr. No. 4. London.

Walton, H. J. (1958). F. ment. Sci., 104, 884

\title{
Attempted Suicides from Intact and Broken Parental Homes
}

\author{
S. GREER,* M.D., D.P.M. ; J. C. GUNN, † M.в., CH.B.
}

Brit. med. F., 1966, 2, 1355-1357

In a previous paper a comparative study of patients admitted to hospital because of suicidal attempts and matched nonsuicidal controls is described (Greer, Gunn, and Koller, 1966). Statistical correlations were demonstrated between suicidal behaviour and parental loss in childhood, which was defined as loss or continuous absence for at least 12 months of one or both natural parents before the age of 15 . Compared with non-suicidal controls, the suicidal patients had a significantly higher incidence of parental loss, and such loss more commonly involved both parents, occurred at a younger age, and was more frequently due to irreversible causes (i.e., parental death and divorce). The findings provide evidence for a relation between attempted suicide and parental loss. It should be noted, however, that this childhood experience occurred in only $49 \%$ of suicidal patients. It is therefore pertinent to seek information about predisposing factors in those patients who have not suffered parental loss, and to determine, if possible, whether the circumstances associated with suicidal behaviour differ among patients from broken and intact homes.

\footnotetext{
* Lecturer in Psychological Medicine, King's College Hospital, London. † Registrar, Maudsley Hospital, London.

From the Department of Psychological Medicine, King's College Hospital, London.
Hom
}

D
With these aims in view, the present paper reports detailed comparisons between suicidal patients who had experienced parental loss and those from intact homes in respect of a number of salient variables. All patients admitted to King's College Hospital for attempted suicide between 1 March and 1 September 1965 (with the exception of three patients who discharged themselves immediately after admission) were included in our study, the relevant information being obtained from interviews with patients and, in some cases, their relatives. A detailed description of the sample has been given (Greer et al., 1966).

\section{Findings}

The total sample comprised 156 suicidal patients, of whom $76(49 \%)$ had experienced childhood parental loss (P.L. group) and $80(51 \%)$ came from intact homes (I.H. group). Statistical comparisons, by means of $\chi^{2}$ and Student's $t$ tests, between the P.L. and I.H. groups are outlined below.

Age Distribution (Table I).-Though differences between the age distributions as a whole did not reach statistical significance, separate comparisons within each age group revealed that a 
slgnificantly higher proportion of I.H. patients were aged 50 and over than was the case among P.L. patients.

\begin{tabular}{|c|c|c|c|c|}
\hline \multirow{2}{*}{$\begin{array}{l}\text { Patient } \\
\text { Group }\end{array}$} & \multicolumn{4}{|c|}{ Age in Years } \\
\hline & Under 30 & $30-49$ & 50 and Over & Total \\
\hline $\begin{array}{l}\text { P.L. } \\
\text { I.H. }\end{array}$ & $\begin{array}{l}40(53 \%) \\
39(49 \%) \\
\end{array}$ & $\begin{array}{l}28(37 \%) \\
24(30 \%)\end{array}$ & $\begin{array}{r}8(10 \%) \\
17(21 \%) \\
\end{array}$ & $\begin{array}{l}76 \\
80 \\
\end{array}$ \\
\hline Sig. of diff. & Not significant & Not significant & $\begin{array}{c}\text { C.R. }=2.28 \pm 0.06 \\
P<0.025\end{array}$ & \\
\hline
\end{tabular}

Sex Ratio.-The ratio of females to males was found to be 2.6:1 in the P.L. group and $1.9: 1$ in the I.H. group. These differences are not significant.

Marital State.-No significant differences were found with respect to marital state, although a greater proportion of I.H. patients $(38 \%)$ than P.L. patients $(24 \%)$ were single (C.R. $=1.85 \pm 0.07 ; \mathrm{P}>0.05$ ).

Social Class.-The social-class distribution (General Register (Office, 1960) was closely similar among the P.L. and I.H. patients.

Country of Origin.-Differences between P.L. and I.H. Britain, 13\% came from other Western countries, most commonly patients were negligible. In each group about $79 \%$ were born in Ireland, $4 \%$ from the West Indies, and 4\% from Afro-Asian countries. All patients except one had lived in Britain for at least 12 months.

Material Circumstances.-These were assessed according to the housing conditions and financial state of patients. Both groups were similar with respect to material circumstances, which were rated as poor (i.e., a person/room ratio of at least 1.5:1 and/or gross financial hardship) among 12\% of P.L. patients and $9 \%$ of patients from intact homes.

Physical Illness.-Almost identical proportions of P.L. (11\%) and I.H. (13\%) patients had various physical illnesses or operations (as listed in our previous paper) during the six months preceding admission for attempted suicide.

Previous Suicidal Attempts.-At least one previous suicidal attempt had been made by $29 \%$ of P.L. patients and $25 \%$ of the I.H. group. The differences are clearly insignificant.

Social Isolation.-This was recorded where patients had been living entirely alone for at least six months before admission. Both groups were similar with regard to social isolation, which was found in $14 \%$ of P.L. and $20 \%$ of I.H. patients.

Interpersonal Relations (Table II).- Two specific aspects of patients' interpersonal relations during the six months preceding the suicidal attempt were investigated: (1) the presence or absence of close relationships (i.e., relationships which the patient considered important), and (2) disruption of close relationships (i.e., a threatened or actual break as a result of interpersonal conflict). A small proportion of patients in each

\begin{tabular}{|c|c|c|c|c|c|}
\hline \multirow{2}{*}{$\begin{array}{l}\text { Patient } \\
\text { Group }\end{array}$} & \multicolumn{5}{|c|}{ Close Relationships within 6 Months of Admission } \\
\hline & Disrupted & $\begin{array}{c}\text { Not } \\
\text { Disrupted }\end{array}$ & $\begin{array}{c}\text { No Close } \\
\text { Relationship }\end{array}$ & Total & $*$ \\
\hline $\begin{array}{l}\text { P.L. } \\
\text { I.H. }\end{array}$ & $\begin{array}{l}31(44 \%) \\
20(26 \%)\end{array}$ & $\begin{array}{l}35(50 \%) \\
50(66 \%) \\
\end{array}$ & $\begin{array}{l}4(6 \%) \\
6(8 \%) \\
\end{array}$ & $\begin{array}{l}70 \\
76 \\
\end{array}$ & $\begin{array}{l}6 \\
4 \\
\end{array}$ \\
\hline Sig. of diff. & $\begin{array}{c}\text { C.R. }=2.30 \pm 0.08 \\
\mathbf{P}<0.025\end{array}$ & - & Not significant & & \\
\hline
\end{tabular}

* Evidence inconclusive or unconfirmed.

group were found to have no close relationships of any kind, the differences between P.L. and I.H. patients being insignificant. However, as shown in Table II, a significantly greater proportion of patients from broken homes had experienced recent disruption of a close relationship (44\%) than was the case among patients from intact homes $(26 \%)$.
Psychiatric Diagnosis (Table III).-Diagnosis was based on the criteria outlined in the diagnostic manual of the American Psychiatric Association (1952). Patients were classified in the following categories: (1) neurotic disorders, including personality disorders other than sociopathic personality ; (2) psychotic disorders-schizophrenia and manic-depressive illness ; (3) organic brain disorders, which included five epileptics and one patient with cerebral arteriosclerosis; (4) sociopathic personality (psychopaths); and (5) acute situational reaction (i.e., no evidence of psychiatric disorder, the suicidal attempt having been made in the face of severe stress by an essentially normal personality). Patients from broken and intact homes differed significantly in the following respects: (1) The I.H. group contained a higher proportion of patients with schizophrenic and manic-depressive illnesses, and a lower proportion of sociopaths than the P.L. group. (2) The incidence of all psychiatric illness except sociopathic disorder (i.e., neuroses, psychoses, and organic brain disorders taken together) was significantly greater among I.H. (88\%) than P.L. $(68 \%)$ patients (C.R. $=2.87 \pm 0.07$; D.F. $155 ; \mathrm{P}<0.01)$.

\begin{tabular}{|c|c|c|c|c|c|c|}
\hline \multirow[b]{2}{*}{$\begin{array}{l}\text { Patient } \\
\text { Group }\end{array}$} & \multicolumn{5}{|c|}{ Diagnosis } & \multirow[b]{2}{*}{ Total } \\
\hline & Neuroses & Psychoses & $\begin{array}{c}\text { Organic } \\
\text { Brain } \\
\text { Disease }\end{array}$ & $\begin{array}{c}\text { Socio- } \\
\text { pathic } \\
\text { Personality }\end{array}$ & $\begin{array}{c}\text { No } \\
\text { Psychiatric } \\
\text { Illness }\end{array}$ & \\
\hline $\begin{array}{l}\text { P.L. } \\
\text { I.H. }\end{array}$ & $\begin{array}{l}47(62 \%) \\
55(69 \%)\end{array}$ & $\begin{array}{c}3(4 \%) \\
11(14 \%)\end{array}$ & $\begin{array}{l}2(3 \%) \\
4(5 \%)\end{array}$ & $\begin{array}{c}14(18 \%) \\
3(4 \%)\end{array}$ & $\begin{array}{c}10(13 \%) \\
7(9 \%)\end{array}$ & $\begin{array}{l}76 \\
80 \\
\end{array}$ \\
\hline Sig. of diff. & $\begin{array}{c}\text { Not } \\
\text { significant }\end{array}$ & $\begin{array}{c}\text { C.R. }= \\
2.13 \pm 0.03 \\
P<0.05\end{array}$ & $\begin{array}{c}\text { Not } \\
\text { significant }\end{array}$ & $\left|\begin{array}{c}\text { C.R. }= \\
2.92 \pm 0.06 \\
P<0.005\end{array}\right|$ & $\begin{array}{c}\text { Not } \\
\text { significant }\end{array}$ & \\
\hline
\end{tabular}

Medical Danger of Suicidal Attempt.-The suicidal attempt was rated as "very dangerous" where death was considered highly probable without medical intervention, "some danger" where any risk to life or health was involved, and "harmless" where there was no risk whatsoever. Differences between the P.L. and I.H. groups were insignificant. Very dangerous attempts were made by $9 \%$ of P.L. and $6 \%$ of I.H. patients, some danger was involved in $57 \%$ of P.L. and $56 \%$ of I.H. patients, and the suicidal attempts of the remaining $34 \%$ of P.L. and $38 \%$ of I.H. patients were regarded as harmless.

\section{Discussion}

In the present sample of attempted suicides patients from broken homes and those from intact homes were found to be similar in respect of sex ratio, marital state, social class, country of origin, material circumstances, associated physical illness, incidence of previous suicidal attempts, social isolation, and degree of danger involved in the suicidal act. On the other hand, a number of significant differences were demonstrated. Patients who had suffered parental loss in childhood were almost always under 50 years of age, a considerable number $(18 \%)$ were sociopaths, and nearly half the group had experienced recent disruption of a close interpersonal relationship. In contrast, the group who came from intact homes included proportionately more patients aged 50 and over; only $4 \%$ were sociopaths, whereas the incidence of other psychiatric disorders -in particular, schizophrenic and depressive psychoses-was significantly higher; and in only a quarter was the suicidal attempt preceded by disruption of close relationships.

In considering the implications of these findings it is necessary to examine what has been termed disruption of interpersonal relations in more detail. This situation was judged to have occurred where interpersonal conflict had led to an actual break or the threat of imminent separation in a close relationship within six months of admission to hospital. Such experiences consisted of broken love-affairs or marriages in every case except one (where a parent-child relationship was severed by the father of a patient because of her association with 
a married man). Our figures represent a conservative estimate of the incidence of recent disruption in close relationships, since only those cases in which the evidence was unequivocal and confirmed by relatives or friends were included.

Disruption of interpersonal relationships was correlated with attempted suicide in the present study (Greer et al., 1966), and a statistical association was also demonstrated between such disruption and parental loss in childhood. The adverse social circumstances and background of attempted suicides, so clearly described by Kessel (1965), pertained in approximately one-half of the present sample. These patients came from broken homes, their suicidal attempts were often preceded by disruption of a close relationship, and a substantial minority were sociopaths (the proportion being more than four times as high as that among patients from intact homes). Thus suicidal behaviour in one group of patients was associated with parental loss, personality disorder, and disruption of interpersonal relationships, and each of the latter two variables was correlated with parental loss. These results provide support for the observations of Kessel (1965), who noted the frequency of parental absence and poor interpersonal relationships among his patients and speculated: "Whether the broken parental home is the root from which stems the disorganized life-pattern, the disorganized marriage ... of ten found in the stories of people who poison themselves."

The remaining half of the present sample came from intact homes, sociopathic personality disturbance was rare, and recent disruption of relationships significantly less common. As we have seen, the patients in this group were older, and schizophrenic and depressive psychoses were more than three times as frequent as among patients from broken homes. It is probable that psychotic illness contributed to suicidal behaviour here, but since only $14 \%$ of the patients from intact homes suffered from functional psychoses it is evident that other, as yet unknown, predisposing factors were operative in this group.

The suicidal patients who had experienced parental loss in childhood and those who came from intact homes showed many similarities. Nevertheless, the circumstances associated with suicidal behaviour differed in each group in several important respects. The present findings indicate the possibility of distinct, though overlapping, subgroups among attempted suicides. The delineation of such categories is of heuristic importance and warrants further investigation. In this connexion it is suggested that studies of larger patient-samples, enabling the use of more sophisticated statistical techniques such as multivariate analysis, should prove fruitful.

\section{Summary}

In a consecutive series of 156 attempted suicides admitted to a general hospital comparisons were made between patients who had suffered parental loss in childhood $(\mathrm{N}=76)$ and those who came from intact homes $(\mathrm{N}=80)$ with regard to a number of variables.

Patients from broken and intact homes were found to $\mathrm{tc}$ similar in terms of sex ratio, marital state, social class, couniry of origin, material circumstances, preceding physical illness, incidence of previous suicidal attempts, social isolation, and seriousness (i.e., medical danger) of the present suicidal attempt.

Statistically significant differences were demonstrated between patients from broken and intact homes in the following respects : (1) age, the group from intact homes included a higher proportion of patients aged 50 and over ; (2) diagnosis-schizophrenic: and psychotic depressive illnesses were more common and sociopathic personality disturbance less common among patients from intact homes than among the group from broken homes ; and (3) disruption of a close interpersonal relationshipthis experience preceded suicidal attempts more often among patients from broken homes than among those from intact homes.

The possibility of two distinct, though overlapping, groups within the present sample of suicidal patients is considered and the need for further studies aimed at identifying subgroups of attempted suicides is stressed.

We are grateful to Dr. D. Liddell, head of the department of psychological medicine, for his advice and guidance. Our thanks are also due to Mrs. R. Badham for secretarial work.

\section{REPERENCES}

American Psychiatric Association (1952). Diagnostic and Statistical Manual of Mental Disorders. Washington.

General Register Office (1960). Classification of Occupations. H.M.S.O. London.

Greer, S., Gunn, J. C., and Koller, K. M. (1966). Brit. med. Y., 2, Kessel, N. (1965). Ibid., 2, 1265.

\title{
Modified Technique for Long-term Endocardial Pacemaking*
}

\author{
M. S. GOTSMAN, M.D., M.R.C.P., M.R.C.P.GLASG., D.T.M.\&H.; W. BECK, M.SC., M.MED., M.R.C.P. \\ L. W. PILLER, F.S.C.T. ; S. C. W. BOSMAN, M.B., CH.B.; C. N. BARNARD, M.D., M.MED., M.S., PH.D., P.A.C.s. \\ V. SCHRIRE, M.D., M.SC., PH.D., F.R.C.P.ED., F.R.C.P., F.A.C.C.
}

Brit. med. 7., 1966, 2, 1357-1360

Transvenous endocardial pacemaking with a subcutaneous implanted generator is now established as a satisfactory method of long-term pacing in patients with complete heart-block (Furman, Schwedel, Robinson, and Hurwitt, 1961 ; Siddons and Davies, 1963 ; Harris, Bluestone, Busby, Davies, Leatham, Siddons, and Sowton, 1965 ; Bluestone, Davies, Harris, Leatham, and Siddons, 1965). In the elderly patient it avoids thoracotomy, the hazards of surgery, and postoperative chest complications.

The transvenous technique, although simple, is still not faultfree. There are mechanical and electronic problems with displacement of the electrode tip and defective pacing, faults in the units or connexions, unexplained rise in endocardia! threshold, and fractured electrode wires. Biological problems such as perforation of the myocardium, cervical and axillary wound breakdown, septicaemia, pulmonary embolism, and ventricular tachycardia also occur (Davies and Siddons, 1965 ; Bluestone et al., 1965 ; Harris et al., 1965).

We have used the transvenous method of endocardial pacing with a generator implanted in the axilla since October 1964.

\footnotetext{
- From the Cardiac Clinic, the Departments of Medicine and Surgery, the University of Capetown and the Cardiovascular-Pulmonary Research Group, supported in the Department of Medicine by the Search Group, supported in the Department 1 U.S.C.I. Catheter Co., Glen Falls, New York.
} 